\title{
Negative Emotions Damage the Heart
}

\author{
Edith María Beltrán Molina*, Ana Beatriz Peña Mantilla and Durvys Rosa Vázquez Pérez \\ Assistant Professor at the University of Sancti Spíritus "José Martí Pérez", Cuba
}

*Corresponding author: Edith María Beltrán Molina, Assistant Professor at the University of Sancti Spíritus "José Martí Pérez", Cuba

\section{ARTICLE INFO}

Received: 幽 October 05, 2021

Published: 幽 October 18, 2021

Citation: Edith María Beltrán Molina, Ana Beatriz Peña Mantilla, Durvys Rosa Vázquez Pérez. Negative Emotions Damage the Heart. Biomed J Sci \& Tech Res 39(3)-2021. BJSTR. MS.ID.006296.

\section{ABSTRACT}

This article reflects on the consequences that the emotional changes that we are suffering during life can suffer and how these can cause negative effects on the heart and even cause death if we do not respond adequately to them.

Keywords: Emotions; Suffering; Heart; Human Organism

\section{Introduction}

The heart (from the Latin cor) is the main muscular organ of the circulatory system. In humans, it is a hollow muscle located in the thoracic cavity with a slight inclination to the left whose function is to pump blood throughout the body through the blood vessels. The heart muscle is myogenic, that is, it excites itself. Rhythmic contractions occur spontaneously, as well as their frequency, which can be affected by the response of our body to different situations that may arise in the course of life, including:

1. Surprise: a fleeting and unexpected emotion.

2. Perception of a danger.

3. A dislike at work.

4. Jealousy.

5. An illness.

6. The infidelity of the partner or spouse.

7. The culmination of a loving or fraternal relationship.

8. The loss of a loved one.

9. An energetic discussion with someone.

10. Social exclusion.
Among the most recurrent emotional symptoms of people who have suffered from such ailments, we could mention:

1. Suffering

2. Principles of despair and insanity.

3. Loss of meaning towards life and daily tasks.

4. Moods such as: sadness, melancholy, depression.

5. Negative emotional arousal (irritation, anger, impatience, anxiety)

6. Very strong stress

All this can affect the normal functioning of our body causing physical symptoms such as: tachycardia, chest pain, fatigue, asthma, diarrhea, eczema and other skin conditions, lack of sleep, physical exhaustion, lack of appetite, or due to on the contrary, a voracious appetite, muscle spasms, among others, but they also directly, and sometimes seriously, affect the heart. There are studies that address the effects on the heart after receiving bad news and suffering severe emotional stress, one of them is temporary heart failure commonly called broken heart syndrome or Tako-tsubo cardiomyopathy, (this is the name of a vessel, domed and narrow 
neck traditionally used by Japanese fishermen to catch octopus) which was first described in the 1990s in Japan. It is a stressinduced cardiomyopathy in which there is a sudden temporary weakening of the myocardium. Chest pain is one of the common signs of this disease. From research carried out, it has been possible to determine that many of the cardiovascular problems that occur are mainly caused by depression [1-3].

\section{What Happens in our Body When We are Depressed?}

The body of a depressed person sets in motion a series of substances from structures and glands that regulate their functioning. Among them are the hypothalamus in the brain, which issues orders for the pituitary to order the thyroid to produce thyroid hormones, these streamline all functions and, in turn, act on the adrenal glands, where adrenaline is produced, High doses of this hormone have a strong impact on blood pressure, heart rate and the size of the arteries of the heart. Also, the levels of serotonin (a neurotransmitter that helps calm and produces a feeling of wellbeing) fall; If this situation is recurrent, inflammatory responses can occur, a tendency to arrhythmias and a decrease in cardiac flow; which can cause heart attacks and sudden death. Therefore, scientists support the theory that people who cannot adapt and overcome emotional pain, are those who must go through a higher level of physical pain. Many people manage to adapt to these situations, but many others do not reach those levels of resilience (the ability to be reborn after adversity).All this without taking into account also that depressed people tend to adopt unhealthy lifestyles, evidenced in bad eating habits, the tendency to smoke sedentary lifestyle and even alcoholism, therefore, there is a dangerous increase in risk factors coronary.

We are not exempt from encountering situations that push us to our limits, what is truly important is that the rational part enables us better or worse to face these changes. Under new conditions or any change that requires a biological adaptation process, man can respond in an exaggerated way for fear of punishment, not finding a reasonable way out, he ends up acting effusively. Negative emotions adversely affect our health, they can contribute to the development

\section{ISSN: 2574-1241}

DOI: $10.26717 /$ BJSTR.2021.39.006296

Edith María Beltrán Molina. Biomed J Sci \& Tech Res

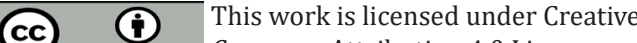

Commons Attribution 4.0 License

Submission Link: https://biomedres.us/submit-manuscript.php of diseases and interfere with recovery, the way you react to them is extremely important. Avoid disorders and learn from what has been lived. Episodes of sadness should help us learn, take new directions and emerge stronger [4-6]. A sad brain produces less serotonin; If we cannot get out of this state by making new decisions and assuming what happened, in the long term this deficit in serotonin can cause us to suffer diseases such as depression, compulsive obsessions and / or violent outbursts. But we have to be strong and find in those moments of meditation, reflection and look for new resources with which to get ahead. If sadness is of any use to us, it is to learn from what we have experienced, we all know that existence is not a flat easy road to travel, there are stones to overcome and new paths to find, realities from which we must learn. This is how we will be stronger and more capable.

\section{Conclusion}

In life no one is exempt from the difficult situations that can arise. We must be prepared to face them, no matter how difficult it may seem. Do not seek solutions that further harm our health such as frequent ingestion of alcoholic beverages, addiction to cigarettes, resorting to diets that alter blood pressure, assuming a sedentary life, staying in unhealthy environments, among others. Learning to overcome and remedy our emotional and physical pain with favorable solutions for our body will allow us to contribute to "heal the hearts" of others.

\section{Conflict of Interest}

No conflict of interest with any institution/organization.

\section{References}

1. Bisquerra R (2009) Psychopedagogy of emotions. Madrid: Synthesis, p: 73.

2. Emotional education and well-being. Rafael Bisquerra Alzina Editorial Cisspraxis.

3. (2020) The broken heart and physical pain.

4. Broken heart syndrome.

5. (2010) Depression and suffering affect heart health.

6. The worst emotions for the heart.

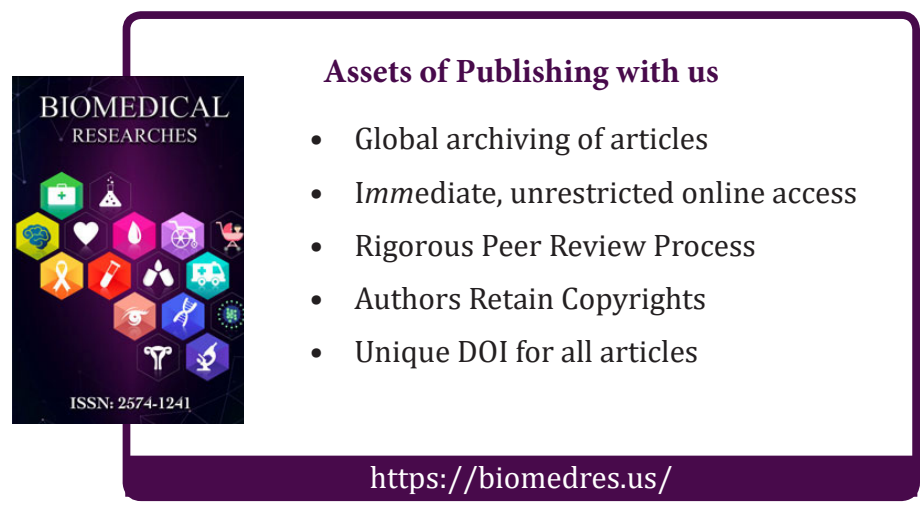

Copyright@ Edith María Beltrán Molina | Biomed J Sci \& Tech Res | BJSTR. MS.ID.006296. 